\section{OPEN ACCESS}

Edited by:

Monica Serra,

The University of Texas Health Science Center at San Antonio, United States

Reviewed by:

Mario Inacio,

University Institute of Maia, Portugal

Sun Jae Won,

Catholic University of Korea,

South Korea

*Correspondence:

Joseph P. Stains

jstains@som.umaryland.edu

Specialty section:

This article was submitted to

Rehabilitation for Musculoskeletal

Conditions,

a section of the journal

Frontiers in Rehabilitation Sciences

Received: 24 September 2021

Accepted: 10 November 2021

Published: 06 December 2021

Citation:

Leser JM, Harriot A, Buck HV Ward CW and Stains JP (2021) Aging,

Osteo-Sarcopenia, and

Musculoskeletal

Mechano-Transduction

Front. Rehabilit. Sci. 2:782848.

doi: 10.3389/fresc.2021.782848

\title{
Aging, Osteo-Sarcopenia, and Musculoskeletal Mechano-Transduction
}

\author{
Jenna M. Leser, Anicca Harriot, Heather V. Buck, Christopher W. Ward and \\ Joseph P. Stains * \\ Department of Orthopaedics, University of Maryland School of Medicine, Baltimore, MD, United States
}

The decline in the mass and function of bone and muscle is an inevitable consequence of healthy aging with early onset and accelerated decline in those with chronic disease. Termed osteo-sarcopenia, this condition predisposes the decreased activity, falls, low-energy fractures, and increased risk of co-morbid disease that leads to musculoskeletal frailty. The biology of osteo-sarcopenia is most understood in the context of systemic neuro-endocrine and immune/inflammatory alterations that drive inflammation, oxidative stress, reduced autophagy, and cellular senescence in the bone and muscle. Here we integrate these concepts to our growing understanding of how bone and muscle senses, responds and adapts to mechanical load. We propose that age-related alterations in cytoskeletal mechanics alter load-sensing and mechano-transduction in bone osteocytes and muscle fibers which underscores osteo-sarcopenia. Lastly, we examine the evidence for exercise as an effective countermeasure to osteo-sarcopenia.

Keywords: bone, muscle, microtubules, mechanotransduction, sarcopenia, cytoskeleton, osteopenia, osteoporosis

\section{INTRODUCTION}

With advancing age, a threshold of decline in the mass and function of bone and muscle marks the onset of musculoskeletal frailty. This loss of muscle and bone quality, collectively called osteo-sarcopenia, initiate changes in lifestyle, and activity levels that start a sequence of events that lead to significant morbidity and even mortality. Indeed, muscle and bone health are remarkably predictive of biological health. Muscle mass or performance, including grip strength and gait speed, and bone mass or hip fracture have all been correlated to increased morbidity and mortality (1-10). Likewise, the incidence of low impact fractures steeply inclines in the osteo-sarcopenia population, contributing to reduced mobility and independence, increased mortality, and corresponding to increased financial burdens (10-13).

Both men and women experience peak bone mass around 30 years of age, with a steady decline for the rest of life thereafter (14). In parallel, muscle strength substantially declines with age followed by declines in muscle mass too (15). When overlaid, the loss of bone mineral density (BMD), muscle strength, and muscle mass, occurs concomitantly suggesting the processes happen in parallel, or are interdependent (16). Since bone and muscle are known to regularly remodel in response to ever changing mechanical cues, cellular dysfunction caused by aging results in a significant decrease in musculoskeletal formation, thus favoring catabolic processes leading to osteopenia and sarcopenia (osteo-sarcopenia). 
Aging related changes to musculoskeletal tissues are multifactorial and include reduced activity levels, chronic lowgrade inflammation, oxidative stress, and impaired autophagy, among others. Together, these factors conspire to initiate a feed forward loop of global changes in bone and muscle cell gene expression $(17,18)$, tissue composition, and tissue functions that exacerbates osteo-sarcopenia (19-21) termed the cycle of frailty (Figure 1). The initiation of the cycle of frailty poses a "chicken or the egg" paradox when it comes to reductions in activity, bone mass, and muscle mass. It has yet to be determined whether the onset of the cycle of frailty starts as aging-related changes to bone and muscle which cause individuals to become less active, or if inactivity causes aging-related declines in muscle and bone. What can be said with certainty is that the cycle is a feed-forward loop where inactivity, regardless of the reason, causes disuse of bone and muscle, thusly reducing strength, weakening balance, and increasing fracture risk, ultimately furthering inactivity. Accordingly, therapeutic targets to improve bone and muscle mass and function have tremendous potential to disrupt this feed forward cycle and lead to better patient outcomes.

Bone and muscle sense and respond to their mechanical demands by adjusting their mass and quality. This permits the musculoskeletal system to adapt to changing activity levels to accommodate function. Muscle must be sufficiently robust to be able to mediate daily activities, which can vary dramatically based on lifestyle. Likewise, within this range of typical activity, bone must be sufficiently strong to bear load without failure (fracture). This ability of cells to sense mechanical events and translate them into biological signals that dictate cell and tissue function is termed mechano-transduction. At an accustomed amount of mechanical loading (i.e., typical daily activity and exercise) bone and muscle operate to maintain function around this homeostatic set point, maintaining and repairing the tissue. This homeostatic setpoint at which slight variance in activity does not prompt net increases or decreases in bone or muscle mass is sometimes referred to as the lazy zone (Figure 2). When muscle and bone experience unaccustomed loads such as a sudden, sustained change in lifestyle (e.g., a rigorous strength training regimen), the cells of these tissues sense and respond to this change activating a mechano-transduction pathway to enter an anabolic phase where new tissue is deposited to accommodate this new stimulus. Eventually, bone and muscle will fully adapt to the new mechanical demands and, if these demands remain sustained and static, this mechanical environment will become an accustomed load and a new homeostatic set point defined at this level of musculoskeletal mass and quality. The converse is true in disuse. A sustained decrease in activity and loading (e.g., bedrest) will be sensed by the cells of bone and muscle and initiate a catabolic phase where the musculoskeletal system adapts to its new mechanical environment by reducing bone and muscle mass, setting a new homeostatic set point around the adapted activity inactivity levels. Indeed, anyone with a limb immobilized in a cast for 12 weeks has experienced the rapid adaptation of muscle mass to disuse through atrophy.
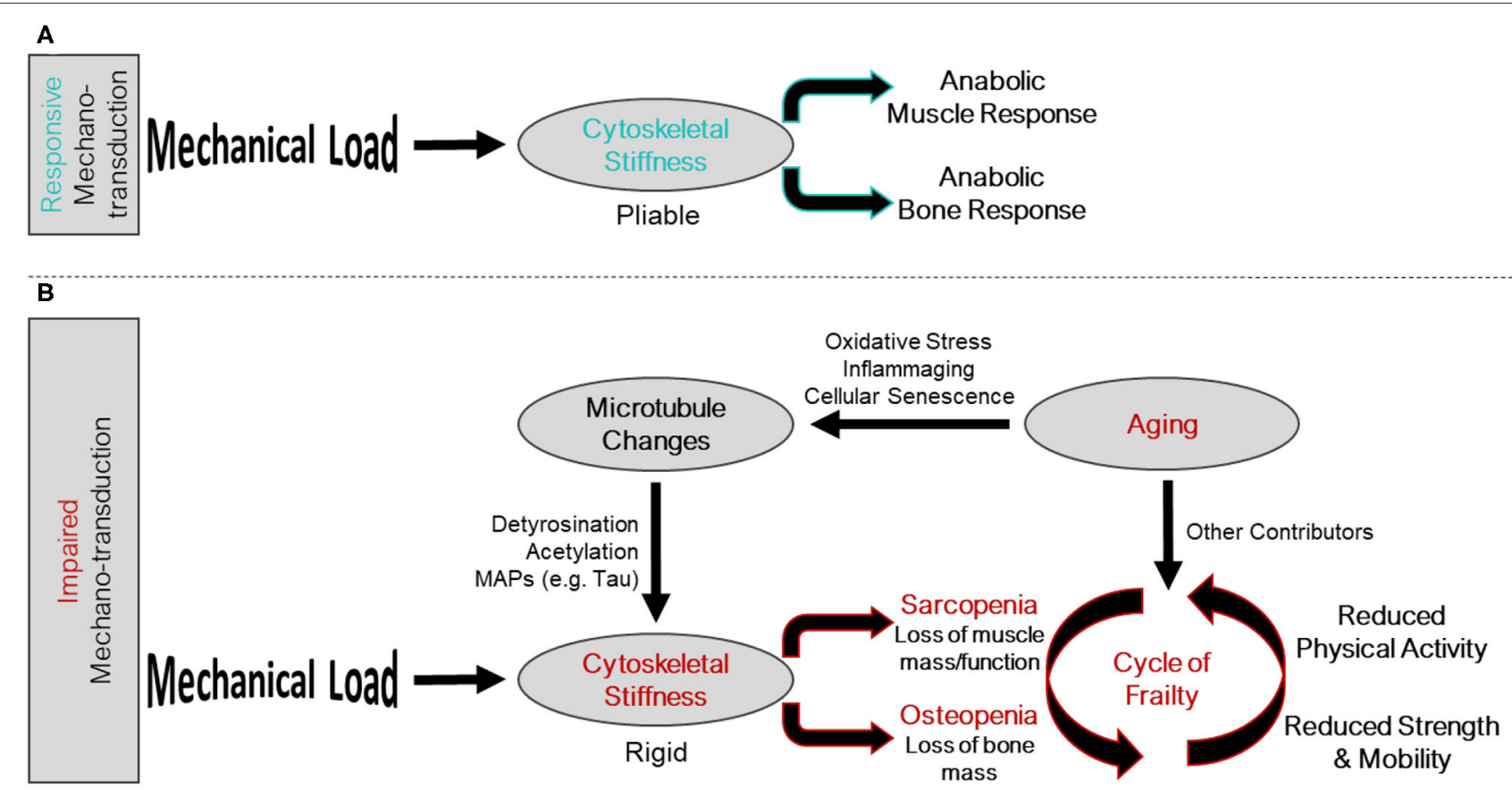

FIGURE 1 | Intersection of the mechano-transduction pathway and the cycle of frailty. (A) Responsive mechano-transduction in youth. Mechanical load is sensed by a pliable cytoskeleton initiating the anabolic responses of both muscle and bone. (B) Impaired mechano-transduction in aging. Mechanical load is sensed by a rigid cytoskeleton, influenced by changes to the microtubule network, a consequence of aging related phenomena, leading to sarcopenia and osteopenia. These musculoskeletal pathologies feed into the cycle of frailty, where reduced strength and mobility, and reduced physical activity propagate the feed forward cycle. 


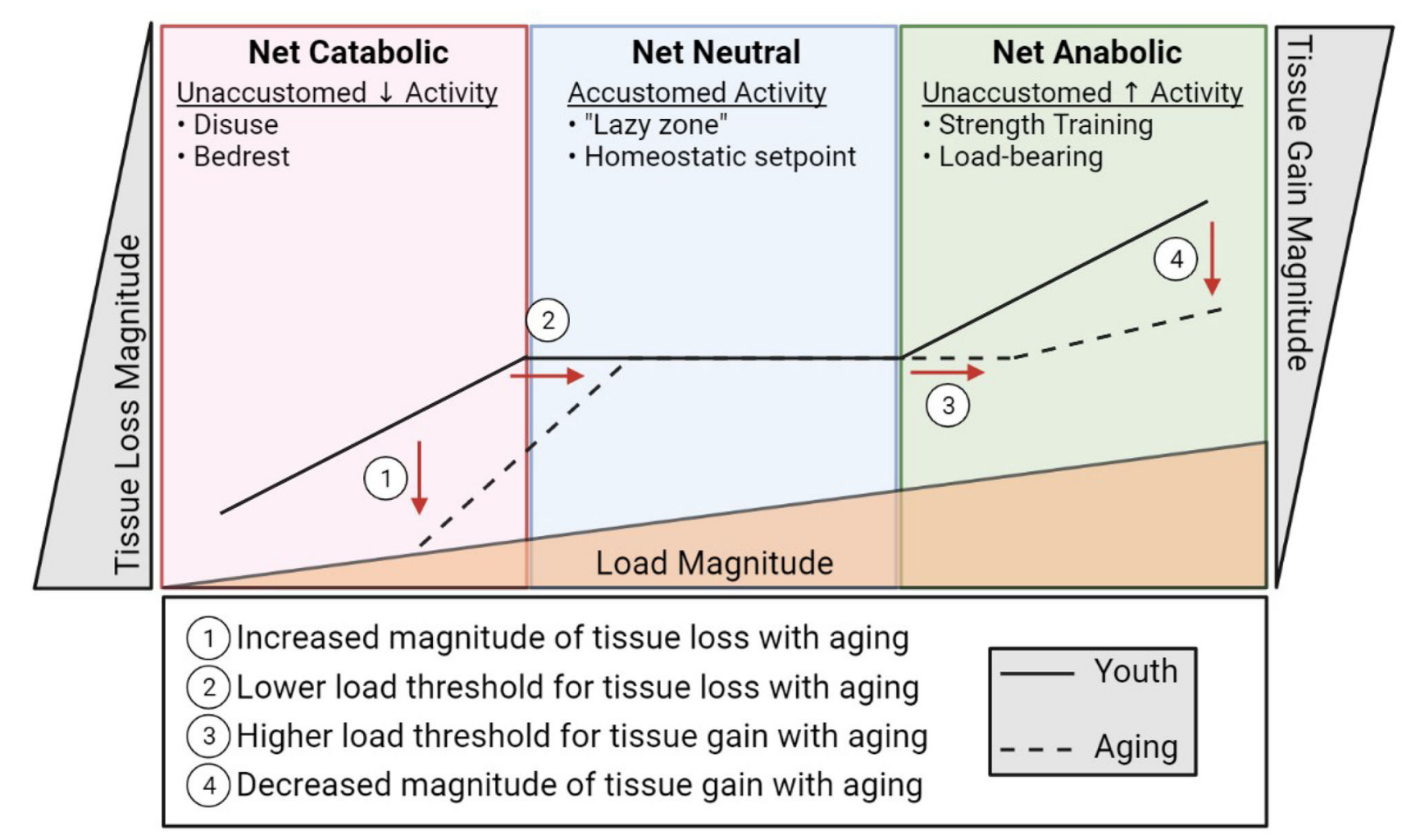

FIGURE 2 | A diagrammatic representation of musculoskeletal catabolic, neutral, and anabolic zones. The solid line represents how load (bottom triangle) influences bone and muscle loss (left), maintenance (center), and creation (right) in youth. The dashed line indicates the apparent shift in load sensitivity (shifted right) and loss/gain magnitude (shifted up/down, respectively) associated with aging.

An insidious feature of aging is that this exquisitely adapted ability to sense and adapt to a changing mechanical environment begins to unravel. In both bone and muscle, the ability to respond to loading is impaired with increasing age (22-24). In rodent models, the ability of bone cells to sense and respond to a mechanical load is reduced in old mice compared to sex matched young mice at various forces $(24,25)$. What this means is that a load capable of stimulating bone formation in young mice is not enough to stimulate bone formation in old mice, and in order to produce comparable new bone in old mice as in young mice, the load in old mice needs to be increased. Essentially, if we over simplify this to an example with weights on a squat bar, a young individual could build bone using $\sim 200 \mathrm{lbs}$, whereas an old individual would have to use $>300 \mathrm{lbs}$ to build new bone. This is not feasible for a population of people who are also ailed by sarcopenia. Not only are osteocytes less stimulated by mechanical load in aging, they are also less capable of responding to the load that they are receiving.

Interestingly, initiation of sarcopenia associates aging with a decline in muscle strength prior to a decline in muscle mass, suggesting functional measures in muscle may be predictive of aging earlier than muscle size (15). Consistent with this concept is the evidence that functional measures of muscle (i.e., grip strength, gait speed) are strong predictors of biological age (15). Given that the hypertrophic response to resistance exercise is reduced in aging relative to youth, yet increases in strength and power are achievable (26-28), the mechano-biology of muscle mass is of primary concern.

Here, we will examine the provocative idea that aging related factors may disrupt the very machinery that bone or muscle cells use to sense and respond to mechanical stimuli. It is important to acknowledge that many of the mechano-sensors and mechano-transduction cascades in bone and muscle are affected by aging and are often interconnected at many levels (29-33). We will focus on an element of a recently described mechano-transduction pathway - the microtubule cytoskeleton - shared by bone and muscle cells, as an example of how aging related changes may influence mechano-transduction pathway (34-37). We think this is a reasonable model upon which to overlay these concepts in that nearly all the mechano-sensitive elements in muscle and bone have been linked directly or indirectly to the cytoskeleton and converge on calcium signals (38-40). Thus, many of these concepts can likely be extended to the other characterized mechano-sensors in musculoskeletal tissues. Additionally, we will survey the current literature suggesting how aging-related dysfunction of the cells in bone and muscle, and specifically their ability to sense and respond to mechanical cues, not only contribute to osteo-sarcopenia, 


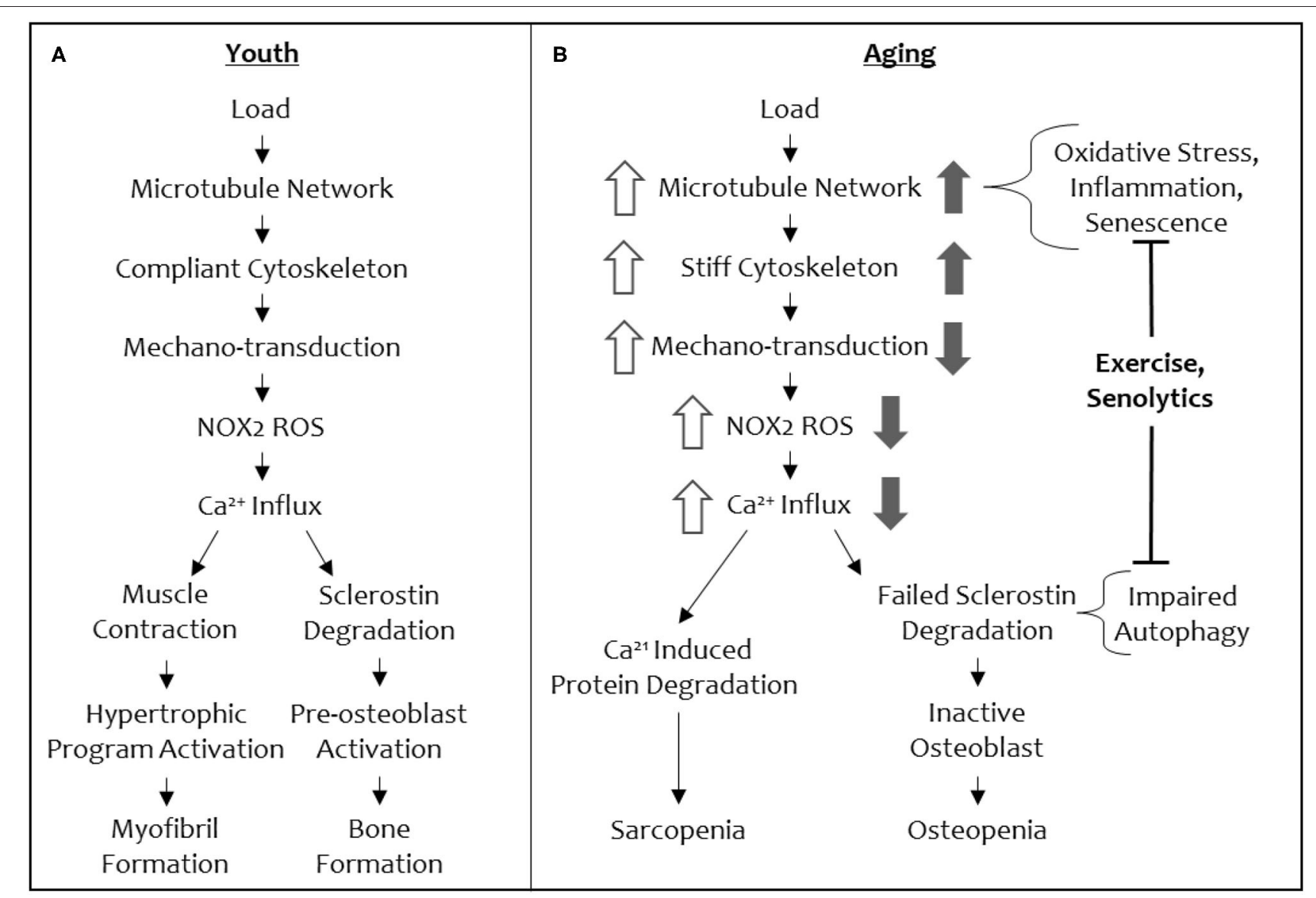

FIGURE 3 | A schematic of the shared mechano-transduction pathway in youth and in aging. Depiction of the shared mechanical load pathway in youth (A) and in aging (B). Changes in signal magnitude by aging-related phenomena are indicated in open arrows (muscle) and solid arrows (bone).

but also may serve as mechanistic targets for future therapy. Finally, we will consider the impact of exercise as a mode of rehabilitation for the mechano-sensing apparatus in aged cells, restoring the homeostatic set point, and improving bone and muscle outcomes.

\section{MUSCULOSKELETAL MECHANO-BIOLOGY}

The cells that facilitate mechano-responsiveness in bone and muscle are the osteocyte and the skeletal muscle fiber, or myofiber. Within these cells, numerous potential mechanosensors, which have various levels of interconnection, have been identified (41-43), including focal adhesions, primary cilia, stretch activated ion channels, actin filaments, and microtubules (40). Mechano-sensors are the first step in sensing a change in accustomed load and translating mechanical cues into biological signals that regulate cellular function. While the multifactorial nature of aging undoubtably influences many of these mechano-sensors (and other aspects of cellular function) contributing to osteo-sarcopenia, alterations common to both osteocytes and myofibers would be an intriguing therapeutic target.

Recently, our groups have defined a mechano-transduction pathway with conserved elements in both bone and muscle (Figure 3). In both tissues, this mechano-pathway includes a subset of microtubules, which are one of the cytoskeletal proteins that regulate the biophysical properties of the cell, cytoskeletal stiffness, the production of ROS from an enzyme, NADPH oxidase 2 (NOX2), and an intracellular calcium response that governs bone and muscle function in response to mechanical loading signals $(34,35)$. Culmination of this mechano-transduction pathway in bone permits bone formation, increasing bone mineral density, and in muscle, this pathway ultimately converges on myofibril formation, increasing muscle mass.

Although many of these elements are shared between bone and muscle, only microtubules function in the same role in this mechano-transduction pathway in both tissues. Microtubules, along with actin and intermediate filaments, comprise the cytoskeleton and acts as a scaffold to support cells in movement and cell division among other mechanical events. Microtubule filaments, comprised of $\alpha / \beta$-tubulin dimers, are compressive elements of a highly interconnected cytoskeleton (44). Post 
translational modifications to tubulin dimers can dictate particular function of a microtubule filament and its associated proteins, resulting in the notion of a "tubulin code" $(45,46)$. Specifically, increases in detyrosinated tubulin and acetylated tubulin allow microtubules to bend, buckle, and transmit mechanical loading signals, increase cytoskeletal stiffness, and impact muscle and bone mechano-transduction (34-36). This subset of post-translationally modified, mechano-responsive microtubules initiates a mechano-transduction cascade by translating mechanical forces into biochemical signals via their interactions with other proteins.

The conservation of microtubules as a mechano-sensory element in muscle and bone presents an intriguing opportunity to understand the concomitant loss of function in both tissues with increasing age, as well a singular therapeutic target (i.e., the microtubule cytoskeleton) to modulate for reversing osteo-sarcopenia. Central to this idea is that microtubules tune cytoskeletal stiffness and that a threshold level of stiffness is required for a mechanical load to initiate signaling (i.e., production of NOX2-ROS, calcium influx, to ultimately increase bone formation and myofibril formation and muscle hypertrophy) through this cascade (Figure 3). If the cytoskeletal stiffness is elevated beyond this threshold by specific microtubule post-translational modifications (e.g., acetylation and detyrosination) or microtubule associated proteins (e.g., Tau) then the mechano-transduction cascade is aberrantly affected (decreased mechano-transduction in bone and increased mechano-transduction in muscle). A loss of cytoskeletal stiffness below a threshold level can also impact mechano-responses in both tissues. Thus, there is a Goldilocks zone of "just right" cytoskeletal stiffness that permits musculoskeletal tissues to respond to mechanical loading cues appropriately. In normal physiology, this threshold level of cytoskeletal stiffness is set by environmental cues that adjust the stiffness to be appropriately adapted to accustomed loads, while remaining responsive to unaccustomed loads.

When cytoskeletal stiffness is increased beyond the Goldilocks zone, an opposite ROS and calcium signaling responses is initiated in muscle (excessive ROS and calcium responses) and bone (attenuated ROS and calcium responses), even though these signal transducers are shared in our mechanopathway (Figure 3). For example, in a mouse model of Duchenne's Muscular Dystrophy, hyper-activation of NOX2 and excessive ROS (i.e., oxidative stress) is connected to muscle injury, damage, and atrophy (47, 48). Similarly, calcium influx is higher with increased cytoskeletal stiffness in muscle, disturbing calcium homeostasis, and promoting atrophy $(49,50)$. This makes inhibition of NOX2 and/or calcium attractive targets to alleviate the progression of sarcopenia. However, unlike muscle, bone loses mechanoactivated NOX2-ROS production and TRPV4-calcium influx when cytoskeletal stiffness is pushed beyond the Goldilocks zone. Given the imperative to address osteo-sarcopenia together, rather than individually, in order to recover from the cycle of frailty, we focus the remainder of this review on the action of microtubules in aging as a potential target for a collective solution.

\section{Bone Mechano-Transduction}

Bone resident osteocytes coordinate the actions of mechanotransduction by direct (cell-to-cell) and indirect (secreted proteins, cytokines, and signaling molecules) communication with bone building osteoblasts on the bone surface through the canalicular system, an elaborate network of "tunnels" through the bone that interconnects osteocytes and surface bone cells (51). A major effector of mechano-transduction regulate loading or disuse is the osteocyte secreted glycoprotein sclerostin.

Sclerostin is a key protein, continuously secreted by osteocytes to prevent bone formation, a measure that keeps the skeleton from becoming a metabolic sink and too heavy to move, however in response to vigorous mechanical stimulus (i.e., unaccustomed load), osteocytes reduce sclerostin abundance allowing for osteoblasts to make new bone appropriate for resisting the force experienced. In rodents, sclerostin protein, and its associated transcript, Sost, are decreased in response to mechanical load $(52,53)$ and increased in response to mechanical unloading $(54$, 55), making sclerostin an important gatekeeper to load-induced bone formation. While the consequences of sclerostin action in humans remains conserved, the acute relationship between sclerostin/SOST and mechanical load is less straight forward given loading exercises increase bone mass (56), yet circulating sclerostin protein (not bone-resident sclerostin) increases acutely after exercise (57). However, as expected based on mouse models, long term exercise reduces serum sclerostin (58). This mild discrepancy between humans and mouse responses might be partially reconciled since serum sclerostin levels, which are the outcome measure in human studies, are not necessarily temporally coupled to bone-resident sclerostin, which is typically directly measured in mouse studies (59). Additionally, unloading in young, healthy humans increases circulating sclerostin (60), an outcome that parallels mouse studies and is consistent with the role of sclerostin as a negative regulator of bone formation. A lack of mechanical loading, or disuse, can shift the balance of bone remodeling to favor osteoclast resorption and decrease bone mass.

The subset of mechano-responsive microtubules and the downstream signaling pathway that we described earlier regulates sclerostin protein abundance $(35,37)$. The resulting outcome of this mechano-transduction pathway is the rapid degradation of sclerostin protein by the lysosome, removing the inhibition on bone formation by osteoblasts and allowing new bone formation to occur (37).

\section{Muscle Mechano-Transduction}

Skeletal muscle mass and performance is also regulated by mechanical demand. Brief rounds of high-load resistance exercise, outside of the accustomed homeostatic setpoint, increases the number of myofibrils and machinery involved in the contractile regulation of the muscle fiber. Recruitment of these organelles/proteins increase the muscle fiber cross sectional area, resulting in muscle hypertrophy (morphology) and increased force production (function) (61-63). Central to these hypertrophic changes are mechanical loading cues (contraction or stretch) that elicit mechano-transduction signaling effectors (IG-F1, Ang-II, ROS, calcium, and phosphorylation) to regulate 
pathways in the muscle fiber [calcineurin-NFAT, rapamycinsensitive mTORC1, and mitogen-activated protein kinase (MAPK)] increasing capacity for transcription and translation $(64,65)$. Additionally, the fusion of myogenic stem cells (satellite cells) to existing myofibrils contributes myonuclei necessary to accommodate the increased transcriptional needs of the hypertrophic program, and assist in repair of the muscle fiber if injury occurred (66). On the other hand, unaccustomed lowload exercise generates improved mitochondrial function and overall oxidative capacity, with little change in muscle fiber size, myonuclei number, or muscle mass, highlighting the mechanical sensitivity, and specificity of the hypertrophic response (67-69).

Similar to the bone, muscle also adjusts its mass to decreased load conditions of bedrest, immobilization, and inactivity. In muscle, the reduction in accustomed load promotes a decline in mass (atrophy) and function by reducing the very same transcription and translation required for hypertrophy. The reduction in myofibrillar content and supporting proteins yields smaller myofibers and thus muscle mass to match the reduced mechanical demand (70-72). Central to agerelated atrophy are increases in pro-inflammatory cytokines, excess cytosolic calcium, and oxidative stress that impairs the hypertrophic responses and underscores a decrease force production independent of the loss in muscle mass (73-77). Here we propose these signals also perpetuate the aging related deficits in mechano-transduction.

\section{MUSCULOSKELETAL AGING: PROBLEMS WITH AGE RELATED CELLULAR STRESS}

Numerous interdependent aging related factors, including senescent cells, chronic low-grade inflammation, oxidative stress, and changes in autophagy may all influence bone and muscle. We will first describe their broad impacts on tissue function before discussing their influence on the cytoskeleton and potential impacts on bone and muscle mechano-transduction.

A major driver of these aging related changes is the accumulation of senescent cells, which activate the innate immune system, promote inflammation, and oxidative stress. Cellular senescence is a protective feature of healthy aging, where cells that have exhausted their abilities to function call attention to themselves in order to be cleared from their environment. A senescent cell acquires the senescence associated secretory phenotype (SASP) which includes secreting numerous inflammatory cytokines and ROS among other traits, to invite innate immune cells to safely destroy the senescent cell $(78,79)$. During aging, the body becomes inundated with chronically senescent cells such that SASP overwhelms local tissues creating a stressful environment that can change the function of remaining cells. Indeed, the aging dependent increase in senescent cells, the SASP factors secreted by these cells, and the activation of the innate immune system contribute to oxidative stress and pro-inflammatory environment of aging. Consequently, senescence has been attributed to depletion of osteoprogenitors (80), whereas clearance of senescent cells in bone prevents agerelated bone loss (81). Acquisition of a senescent phenotype also prevents muscle repair in response to injury, and promotes muscle wasting $(82,83)$.

A consequence of the accumulation of senescent cells is the change from physiologic ROS signaling to pathologic oxidative stress. Cells use reactive oxygen species (ROS) and reactive nitric species (RNS) to trigger biological events, including mechanotransduction. However, the production of these highly reactive free radicals is rapidly buffered or detoxified by a cellular counterresponse known as reduction-oxidation (redox) buffering. When ROS and RNS signals exceed this buffering capacity it becomes damaging oxidative stress. Part of cellular function is adaptation to stress, which can encompass the imbalance between oxidative signaling and oxidative buffering that leads to cellular dysfunction. Aged cells are frequently under oxidative stress because changes in gene expression, impaired mitochondrial function (84), and excessive exposure to oxidative molecules, which occurs during aging-related cellular senescence (85), overwhelm the redox buffering capacity of the cell. Ultimately, this results in oxidative damage to macromolecules disrupting cell cycle progression, autophagy, and gene transcription while promoting inflammation and apoptosis (86). The presence of oxidative stress in aging has been linked to poor bone mineral density measures in men and women, with loss of sex hormones as a compounding factor (87-89). Oxidative stress is a keystone feature of osteo-sarcopenia $(71,77)$, and correlates to reduced gait speed and frailty (90).

In aged individuals, chronic, low-grade inflammation due to overexpression of pro-inflammatory cytokines such as IL-1, IL-6, and TNF, Baylis et al. (91) has been referred to as inflammaging, and contributes to a wide range of diseases, including cancer, arthritis, vascular disorders, and musculoskeletal dysfunction $(92,93)$. For example, cross-talk between inflammatory cytokine signaling and pro-osteoclast activating receptor activator of nuclear factor kappa-B ligand (RANKL) stimulates excessive bone resorption (94), generating a net loss of bone mineral density. Chronic inflammation is also associated with osteopenia in bone (95) and sarcopenia in muscle (96), and in addition is highly correlated with frailty, disability, and mortality (97). Inhibition of IL-6 (SASP component) prevents muscle atrophy (98).

Additionally, aging-related inflammation can trigger skeletal progenitor cell dysfunction, a phenotype that was uncoupled to chronological age using a murine genetic knockout of $N F K b 1$, a transcription factor that is prominent in initializing pro-inflammatory cascades, and restored in aged mice using pharmacological intervention (99). Targeting inflammaging with metformin improved age-related deficits in autophagy and redox buffering (100). Metformin has also been shown to regulate bone marrow mesenchymal stem cells and osteogenic differentiation to improve trabecular bone formation around dental implants in osteoporotic rats (101). The effect of metformin on bone mass is provocative; while there are exceptions (102), in most studies it appears to be that metformin improves bone microstructure in rodent ovariectomized osteoporosis (103-105) and stimulates osteoblast mineralization in vitro through AMP-activated protein kinase (AMPK) (106). While metformin has shown some interesting benefits as a target of aging in mice, significant caveats 
remain, as the benefit of metformin blunts muscle hypertrophy in response to resistance training in aging humans (107). The benefits in mice do not directly translate into benefits for humans. Regardless, metformin's action in rodents is consistent with an important role for inflammation and oxidative stress, and defects in autophagy in aging related deficits in musculoskeletal tissues.

Autophagy is a lysosome-dependent mechanism through which cells regulate cytoplasmic turnover, and an important component of cellular proteostasis. Proteostasis, the balance between protein production and degradation, is held in check in part through the ability of the autophagosome (in addition to the proteasome and endoplasmic-reticulum-associated protein degradation) to remove or recycle malfunctioning, damaged, or unneeded proteins and organelles via fusion with lysosomes (108). In aging, autophagy is reduced, due in part to decreased acidity of the lysosome (109) and decreased expression of autophagy-related proteins (110). This may lead to protein aggregation, which is commonly associated with a variety of disorders and diseases (111). Furthermore, genetic deletion of proteins associated with autophagy can produce an "aged" phenotype (112), typically characterized by a decrease in bone mass $(113,114)$, or decreased muscle strength (115, 116), suggesting the incontrovertible role that autophagy plays in aging.

Notably, autophagy is a downstream consequence of mechano-transduction in both muscle and bone. Mechanical load stimulates autophagy in bone and controls the loaddependent degradation of sclerostin (37). Defects in lysosome activity can impact bone health (117) at least in part through the failure to remove the inhibitor of bone formation, sclerostin (37). In muscle, mechanical load also converges on autophagy with mechano-transduction regulated mTORC1 translocation to the lysosome necessary to elicit the hypertrophic signaling cascade (118). In fact, NOX2-dependent ROS signaling activates lysosomes and autophagic flux, but excess ROS can inhibit autophagy and impact muscle mass and function (48). Through this axis, alterations in autophagy due to aging could contribute to muscle deficits through diminished hypertrophic program activation (119-121).

\section{INFLUENCE OF AGING RELATED CHANGES ON THE CYTOSKELETON AND MUSCULOSKELETAL MECHANO-TRANSDUCTION}

Interestingly, many of the factors associated with aging seem to also influence the microtubule-based mechano-sensor that is conserved in the musculoskeletal system (Figure 1). The cumulative impact of many of these aging related changes, which reportedly increase cytoskeletal stiffness microtubule post translational modification in non-musculoskeletal cells, may partially explain the altered mechano-responsiveness of aged muscle and bone. Many of these aging related factors may push microtubules and cytoskeletal stiffness outside of the mechanoresponsive Goldilocks zone and into a pathological gain (muscle) or loss of function (bone) response that deteriorates tissue quality. This suggests microtubules may be a common therapeutic target to improve muscle and bone function in aging. However, it is important to acknowledge that many mechano-transduction pathways are operant in these tissues $(53,122-128)$ and the sum total of effects of aging related factors on tissue homeostasis certainly extend beyond impacts on microtubule mechano-transduction. Rather, we wish to speculate on microtubules and mechano-transduction as provocative additional players in the onset of osteo-sarcopenia and examine how several aging related factors influence this subset of mechano-sensitive microtubules to lead to an alteration of bone and muscle mechano-transduction.

Increased cytoskeletal stiffness appears to both regulate and be a consequence of cellular senescence (129). Using progeroid syndromes as models to study pre-mature senescence, evidence supports that multiple mechano-transduction pathways become dysregulated with the onset of this aging phenotype (130). Reorganization of the microtubule network is a specific cytoskeletal consequence of senescence, including increased microtubule stability and increased tubulin acetylation (131). Indeed, targeting senescent cells with senolytics has proven to be an incredibly effective generalized therapy to improve musculoskeletal health in rodent models $(98,132,133)$. We predict that removal of senescent cells through senolytics is likely to improve the ability to activate mechano-transduction in musculoskeletal tissues.

Likewise, oxidative stress can impact the cytoskeleton, including microtubules (134). Chronic oxidative stress encourages more frequent microtubule repair, generating a dense microtubule network in cardiomyocytes over time (135). Similarly, pro-inflammatory cytokine signaling promotes increased cytoskeletal stiffness (136) and microtubule rearrangement (137). This potentially interferes with microtubule sensation of load (insensitive in bone, hypersensitive in muscle) and initiation of ROS signaling (reduced in bone, enhanced in muscle) for the mechano-transduction pathway. Indeed, inflammation inhibits mechanically-induced calcium production in osteocytes (138), while resolution of inflammation restarts the anabolic $\mathrm{Wnt} / \beta$-catenin signaling pathway and activates osteoblasts (139).

The drug colchicine presents an appealing opportunity to both ameliorate inflammation and rescue microtubule driven cytoskeletal stiffness. Functional consequences of colchicine action include inhibition of neutrophil migration and inflammatory signal transducers, while its direct action prevents polymerization of microtubules (140). In fact, colchicine shows promise as an effective measure against cardiovascular events, given a feature of the disease is an increase in microtubule density and detyrosination in cardiomyocytes $(141,142)$. Further support for targeting microtubules as a potential therapeutic for mechano-transduction in aging can be found with parthenolide. A specific inhibitor of the enzyme that generates detyrosinated tubulin and therefore also cytoskeletal stiffness, exposure to parthenolide rescued cytoskeletal stiffness and mechano-transduction in myocytes and osteocytes in vitro, and prevented eccentric contraction-induced injury in a murine model of Duchenne's muscular dystrophy 
$(34,35)$. Either of these pharmacologic interventions offer the opportunity to transform a stiff cytoskeletal network back into the mechano-responsive Goldilocks zone, as a way to improve musculoskeletal mechano-transduction.

It is worth noting that the effects of oxidative stress on microtubules may not be perfectly straightforward however. In contrast to chronic oxidative stress, acute treatment of neurons with glutathione disulfide, a pro-oxidant, causes neurons to retract cell processes and reduce the amount of tyrosinated $\alpha$ tubulin relative to vehicle treated cells (143). This parallels agingrelated changes observed in osteocytes in bone. Osteocytes, much like neurons, have an extensive cell process network that resides in the lacunar-canalicular network throughout bone (144). Additionally, these long osteocyte cell processes are mechanoresponsive elements (145). Although the effect of oxidative stress on osteocyte microtubules has not been investigated directly, if osteocytes were to behave like neurons (and yes, they do share a number of physiological similarities (146) then an acute bolus of ROS might deplete mechano-sensing structures resulting in diminished mechano-transduction. Consistent with this predicted effect, osteocytes in aged bone have fewer neuronlike cell processes, and form fewer intercellular connections, which would be predicted to impair their ability to coordinate new bone formation (147) In this condition of advanced aging, strategies to improve redox buffering capacity could act to prevent this catastrophic microtubule loss and maintain the cytoskeleton in the mechanically responsive Goldilocks zone. Alternatively, clinically approved microtubule targeted therapeutics that increase microtubule density and promote its modification by detyrosination and acetylation (i.e., paclitaxel) may effectively protect the microtubule network as recently demonstrated in experimental ischemia reperfusion injury (148, 149), and in models of neurodegeneration (29).

The implication of lysosome activity and autophagy as they relate to microtubules are abundant. With respect to our mechano-signaling pathway, lysosome activity and autophagy are influenced by mechanical loading in both bone and muscle and therefore are affected in these cells based on loading stimuli. Additionally, lysosomes use microtubules to position themselves in the cell to carry out their function. Thus, aging related changes in microtubules, influenced by cellular senescence, oxidative stress, and inflammaging, likely affect autophagy independent of mechano-signaling as well, because microtubules themselves affect lysosome trafficking (150). Lysosomes are positioned throughout the cell by microtubule associated motor proteins, kinesins and dynein $(151,152)$. Specific microtubule post-translational modifications (acetylation, detyrosination, and polyglutamylation) confer preference for particular motors (153-155) while certain MAPs (Tau and MAP2) impede motor movement $(156,157)$. Given the relationships between microtubule post-translational modifications and motors, and microtubule motors and lysosome movement, it is not surprising that post-translational modifications or MAPs could spatially restrict lysosomes to a region of the cell, such as detyrosination (158). This sequestration potentially limits lysosome activity and autophagy. Since degradation of sclerostin protein by the lysosome is an outcome of mechano-transduction in bone that leads to bone formation, and mTORC1 association with the lysosome is an outcome of mechano-transduction in muscle that leads to hypertrophy, we speculate that improvements to bone and muscle catabolism can be achieved through targeting agingdependent influences on microtubules, synergistically activating both mechano-transduction and alleviating impaired autophagy.

\section{EXERCISE}

Exercise is among the most impactful interventions for improving overall health. In fact, the beneficial effects of exercise on longevity, overall health, and musculoskeletal health in the elderly are well-documented (159-163). Evidence that musculoskeletal function (i.e., grip strength, gait speed, fracture) appears a sentinel indicator of age-related frailty has drawn attention to the mechanisms by which musculoskeletal tissues are altered in aging.

Aging is acknowledged as a systemic process that impacts all tissues albeit with a varied trajectory of severity. Common to cellular aging in each tissue is increased cellular senescence, oxidative stress, inflammation, and impaired autophagy. While exercise exerts numerous systemic effects, the cellular benefits are underscored by reduced cellular senescence, oxidative stress, inflammation, and improved autophagy. Here we focus on how these cellular benefits within osteocytes and muscle fibers may act though improving age-altered mechano-transduction to elicit their benefits in bone and muscle.

Exercise is proficient at the clearance of senescent cells. Exercise is connected to reductions in senescence associated markers, such as p16 and p21 among others, in human muscle (164). Others have postulated that exercise potentially reverses osteocyte senescence and promotes osteocyte viability even though it did not improve bone mass (165). As senescent cells are a significant source of oxidative stress and inflammation in bone and muscle that drives increased cytoskeletal stiffness in their cells, clearance of senescent cells by exercise will undoubtedly improve bone and muscle health. We reason that a portion of this improvement will be through a partial normalization of microtubule mechano-transduction.

The benefit of exercise is also from the oxidative stress and inflammation generated as a consequence of exercise itself. It is paradoxical that ROS and inflammatory signals act as intermittent low-grade stressors to elicit the transcriptional regulation of redox buffering and anti-inflammatory cytokines (68) to protect the system long-term for benefit $(161,166)$. These benefits of acute stress are also underscored by evidence that targeting inflammation or oxidative stress alone can be deleterious to exercise adaptation in young recreational athletes. Further evidence is in the elderly treated with metformin, and inhibitor of oxidative stress and inflammation, and exercise, show smaller gains to those exposed to only exercise (167).

Additional benefits of exercise include the stimulation of autophagy and mitochondria protein synthesis through the PCG$1 \alpha$ pathway in aged rodent muscle models $(168,169)$, and increased mitochondrial capacity in elderly humans (170). In both murine and human muscle, lifelong exercise in aged cohorts produced protein expression profiles of increased autophagy, 
including microtubule associated proteins LC3II/LC3I and sequesterome-1 (p62) (171). In muscle, lysosomal activation by exercise goes through a number of pathways including the AMPK/ULK1 (Unc-51-like autophagy activating kinase 1) axis, and the $\mathrm{AKT} / \mathrm{FOXO} 3$ axis (172-174). Intriguing is the evidence in the failing heart where AMPK activation by 5 -aminoimidazole carboxamide ribonucleotide (AICAR) or expression of constitutively active AMP (CA-AMPK) reversed the pathologic remodeling of the microtubule network (i.e., reduced microtubule density and level of detyrosinated tubulin) (175). Given that these interventions model the effects of vigorous exercise training, testing their impact in the musculoskeletal system toward improving mechanotransduction, is of high interest.

In total, the benefits of exercise in the elderly are many. We speculate that among the benefits caused by exercise may be, at minimum, a partial reset of the microtubule cytoskeleton to a mechano-responsive range. While exercise is a clinically significant intervention with regard to musculoskeletal frailty, it is not a panacea. Even with exercise-induced reductions in senescence-associated ROS and inflammation, these consequences of aging are not completely eliminated. We predict that while the systemic benefits of exercise to remove senescence, decrease oxidative stress and inflammation and promote autophagy, exercise alone in unlikely to be sufficient to yield complete restoration of bone and muscle mechano-transduction.

However, not all exercise is equal. The physiological benefits of resistance exercise may be different than low intensity exercise. While low intensity exercise may reap some systemic effects on inflammaging, resistance exercise (unaccustomed load) is necessary to maintain or even improve bone and muscle mass. Resistance exercise, in contrast to low intensity or cardiovascular type exercise, are efficacious in both the young and the elderly for increasing bone and muscle mass (176-181). But for an aging population, osteo-sarcopenia serves as a barrier to executing the magnitude of unaccustomed load necessary for commencement of anabolic programming. Therefore, the key is to try to keep activity as high as tolerable to ensure that the lack of mechanical cues does not lead to unaccustomed unloading which initiates bone and muscle atrophy. While walking and other low impact exercise are not typically considered sufficient load to induce bone and muscle formation during youth, in aging, it could be advantageous to stave off further tissue loss by shifting activity levels to an acceptable accustomed load which preserves tissue maintenance (lazy zone) and away from disuse. Optimal musculoskeletal health during aging is most likely to occur when exercise benefits are overlaid with unaccustomed loading, which may synergistically benefit muscle and bone quality. However, as in youth, the homeostatic set point will adjust to static exercise, and progressive resistance training is the most useful intervention to promote muscle and bone anabolism.

\section{DISCUSSION}

In summary, we present the concept that among the deficits contributing to musculoskeletal frailty is a defect in mechano-transduction. Mechano-sensors present in bone and muscle cells are likely impacted by systemic changes in aging, like senescence, low grade chronic inflammation, oxidative stress, and defects in autophagy. We speculate that these aging related changes tip the homeostatic setpoint for an unaccustomed load to initiate anabolic effects in muscle and bone to be increased. We support that this altered mechano-setpoint accelerates the cycle of frailty. Deficits in mechano-transduction propagate the cycle of frailty through failure to stimulate anabolic programs and through progression of catabolic pathways which lead to osteo-sarcopenia. Agingrelated declines in mechano-transduction are exacerbated by reductions in activity levels. While exercise may help to combat detrimental elements of aging in bone and muscle, it may not suffice to restore bone and muscle formation alone, and unaccustomed loading through progressive resistance training is most certainly needed to improve muscle and bone mass/quality.

Importantly, understanding the molecular mediators of the aging related alteration of mechano-set point provides key therapeutic targets to preserve or increase bone and muscle mass in aging. Truly, reducing senescence, inflammation, oxidative stress, and defective autophagy through exercise or pharmacology, combined with targeting elements of common mechano-transduction cascades to improve mechano-transduction gives us our best strategy to improve musculoskeletal frailty, disrupt the cycle of frailty, and restore or preserve musculoskeletal health in the context of aging. To return to our earlier analogy, we posit that synergistic targeting of aging related systemic changes and mechano-transduction thresholds, such as by targeting microtubules, will allow aged individuals to achieve the same range of anabolic response gained from unaccustomed mechanical loading, such as weights on a squat bar, without having to compensate by providing unachievable loads.

While the aim of this review is to highlight the global changes that occur during aging which impact mechanotransduction in bone and muscle particularly at the shared microtubule level, we want to acknowledge that they are but a portion of the mechano-sensing apparatus. Each of these mechano-sensors or mechano-transduction pathways, while not described in any depth here, are all reasonable targets for affecting musculoskeletal frailty. Furthermore, even within the microtubule-dependent mechano-sensing pathways in muscle and bone, there is much yet to be learned about the role of each tubulin post-translational modification and the prevalence of these modifications in aging. Additionally, the other shared elements of our mechano-transduction pathway, NOX2-ROS and calcium influx, also contain potential for mediating osteo-sarcopenia. Indeed, many factors, like myokines, signal between bone and muscle, and are additional factors to consider when discussing reversal of the cycle of frailty (182-185). Regardless, much future investigation is needed to understand, test and develop targets shared by muscle and bone or communicated between muscle in bone to combat aging. 


\section{AUTHOR CONTRIBUTIONS}

All authors contributed to the conceptualization and writing of this review article.

\section{REFERENCES}

1. Trivedi D, Khaw K. Bone mineral density at the hip predicts mortality in elderly men. Osteoporosis Int. (2001) 12:259-65. doi: 10.1007/s001980170114

2. Gale C, Martyn C, Cooper C, Sayer A. Grip strength, body composition, and mortality. Int J Epidemiol. (2007) 36:228-35. doi: 10.1093/ije/dyl224

3. Hardy S, Perera S, Roumani Y, Chandler J, Studenski S. Improvement in usual gait speed predicts better survival in older adults. J Am Geriatr Soc. (2007) 55:1727-34. doi: 10.1111/j.1532-5415.2007.01413.x

4. Sasaki H, Kasagi F, Yamada M, Fujita S. Grip strength predicts cause-specific mortality in middle-aged and elderly persons. Am J Med. (2007) 120:337-42. doi: 10.1016/j.amjmed.2006.04.018

5. Afilalo J, Eisenberg M, Morin J, Bergman H, Monette J, Noiseux N, et al. Gait speed as an incremental predictor of mortality and major morbidity in elderly patients undergoing cardiac surgery. J Am Coll Cardiol. (2010) 56:1668-76. doi: 10.1016/j.jacc.2010.06.039

6. Studenski S, Perera S, Patel K, Rosano C, Faulkner K, Inzitari M, et al. Gait speed and survival in older adults. JAMA. (2011) 305:50-8. doi: 10.1001/jama.2010.1923

7. Chuang S, Chang H, Lee M, Chia-Yu Chen R, Pan W. Skeletal muscle mass and risk of death in an elderly population. Nutr Metab Cardiovasc Dis. (2014) 24:784-91. doi: 10.1016/j.numecd.2013.11.010

8. Bliuc D, Nguyen N, Alarkawi D, Nguyen T, Eisman J, Center J. Accelerated bone loss and increased post-fracture mortality in elderly women and men. Osteoporosis Int. (2015) 26:1331-9. doi: 10.1007/s00198-014-3014-9

9. Katsoulis M, Benetou V, Karapetyan T, Feskanich D, Grodstein F, PetterssonKymmer U, et al. Excess mortality after hip fracture in elderly persons from Europe and the USA: the CHANCES project. J Intern Med. (2017) 281:300-10. doi: 10.1111/joim.12586

10. Guzon-Illescas O, Perez Fernandez E, Crespí Villarias N, Quirós Donate FJ, Peña M, Alonso-Blas C, et al. Mortality after osteoporotic hip fracture: Incidence, trends, and associated factors. J Orthop Surg Res. (2019) 14:203. doi: 10.1186/s13018-019-1226-6

11. Florence CS, Bergen G, Atherly A, Burns E, Stevens J, Drake C. Medical costs of fatal and nonfatal falls in older adults. J Am Geriatr Soc. (2018) 66:693-8. doi: 10.1111/jgs.15304

12. Kabiri M, Brauer M, Shafrin J, Sullivan J, Gill TM, Goldman DP. Longterm health and economic value of improved mobility among older adults in the United States. Value Health. (2018) 21:792-8. doi: 10.1016/j.jval.2017. 12.021

13. Musich S, Wang SS, Ruiz J, Hawkins K, Wicker E. The impact of mobility limitations on health outcomes among older adults. Geriatric Nursing. (2018) 39:162-9. doi: 10.1016/j.gerinurse.2017.08.002

14. Lu J, Shin Y, Yen MS, Sun SS. Peak bone mass and patterns of change in total bone mineral density and bone mineral contents from childhood into young adulthood. J Clin Densitometry. (2016) 19:180-91. doi: 10.1016/j.jocd.2014.08.001

15. Ferrucci L, de Cabo R, Knuth N, Studenski S. Of Greek heroes, wiggling worms, mighty mice, and old body builders. J Gerontol Series A. (2012) 67:13-6. doi: 10.1093/gerona/glr046

16. Laurent MR, Dedeyne L, Dupont J, Mellaerts B, Dejaeger M, Gielen E. Age-related bone loss and sarcopenia in men. Maturitas. (2019) 122:51-6. doi: 10.1016/j.maturitas.2019.01.006

17. Cardoso AL, Fernandes A, Aguilar-Pimentel JA, de Angelis MH, Guedes JR, Brito MA, et al. Towards frailty biomarkers: candidates from genes and pathways regulated in aging and age-related diseases. Ageing Res Rev. (2018) 47:214-77. doi: 10.1016/j.arr.2018.07.004

18. Kane AE, Sinclair DA. Frailty biomarkers in humans and rodents: current approaches and future advances. Mech Ageing Dev. (2019) 180:117-28. doi: 10.1016/j.mad.2019.03.007

\section{FUNDING}

This work was supported funding from NIH (AR071614, JS and CW; AR063631, JS; AR071618 CW).

19. Budui SL, Rossi AP, Zamboni M. The pathogenetic bases of sarcopenia. Clin Cases Mineral Bone Metabol. (2015) 12:22-6. doi: $10.11138 / \mathrm{ccmbm} / 2015.12 .1 .022$

20. Greco EA, Pietschmann P, Migliaccio S. Osteoporosis and sarcopenia increase frailty syndrome in the elderly. Front Endocrinol. (2019) 10:255. doi: 10.3389/fendo.2019.00255

21. Corrado A, Cici D, Rotondo C, Maruotti N, Cantatore FP. Molecular basis of bone aging. Int J Mol Sci. (2020) 21:3679. doi: 10.3390/ijms21103679

22. Brooks S, Faulkner J. Contractile properties of skeletal muscles from young, adult and aged mice. J Physiol. (1988) 404:71-82. doi: 10.1113/jphysiol.1988.sp017279

23. Chan S, Head S, I. Age- and gender-related changes in contractile properties of non-atrophied EDL muscle. PLoS ONE. (2010) 5:e0012345. doi: 10.1371/journal.pone.0012345

24. Meakin LB, Galea GL, Sugiyama T, Lanyon LE, Price JS. Age-related impairment of bones' adaptive response to loading in mice is associated with sex-related deficiencies in osteoblasts but no change in osteocytes. J Bone Mineral Res. (2014) 29:1859-71. doi: 10.1002/jbmr.2222

25. Turner $\mathrm{CH}$, Takano $\mathrm{Y}$, Owan I. Aging changes mechanical loading thresholds for bone formation in rats. J Bone Mineral Res. (1995) 10:1544-9. doi: 10.1002/jbmr.5650101016

26. Cartee G. Aging skeletal muscle: response to exercise. Exerc Sport Sci Rev. (1994) 22:91-120. doi: 10.1249/00003677-199401000-00006

27. Ferri A, Scaglioni G, Pousson M, Capodaglio P, van Hoecke J, Narici M. Strength and power changes of the human plantar flexors and knee extensors in response to resistance training in old age. Acta Physiol Scand. (2003) 177:69-78. doi: 10.1046/j.1365-201X.2003.01050.x

28. Lee H, Kim I, Sung C, Jeon T, Cho K, Ha Y, et al. Exercise training increases skeletal muscle strength independent of hypertrophy in older adults aged 75 years and older. Geriatr Gerontol Int. (2019) 19:265-70. doi: 10.1111/ggi.13597

29. Baas P, Ahmad F. Beyond taxol: microtubule-based treatment of disease and injury of the nervous system. Brain. (2013) 136:2937-51. doi: 10.1093/brain/awt153

30. Hemmatian H, Bakker AD, Klein-Nulend J, van Lenthe GH. Aging, osteocytes, and mechanotransduction. Curr Osteoporos Rep. (2017) 15:40111. doi: $10.1007 / \mathrm{s} 11914-017-0402-\mathrm{z}$

31. Kirby TJ. Mechanosensitive pathways controlling translation regulatory processes in skeletal muscle and implications for adaptation. J Appl Physiol. (2019) 608-18. doi: 10.1152/japplphysiol.01031.2018

32. Ferrari S, Pesce M. Stiffness and aging in cardiovascular diseases: the dangerous relationship between force and senescence. Int J Mol Sci. (2021) 22:3404. doi: 10.3390/ijms22073404

33. Gorza L, Sorge M, Seclì L, Brancaccio M. Master regulators of muscle atrophy: role of costamere components. Cells. (2021) 10:61. doi: 10.3390/cells10010061

34. Kerr JP, Robison P, Shi G, Bogush AI, Kempema AM, Hexum JK, et al. Detyrosinated microtubules modulate mechanotransduction in heart and skeletal muscle. Nat Commun. (2015) 6:8526. doi: 10.1038/ncomms9526

35. Lyons JS, Joca HC, Law RA, Williams KM, Kerr JP, Shi G, et al. Microtubules tune mechanotransduction through NOX2 and TRPV4 to decrease sclerostin abundance in osteocytes. Sci Signal. (2017) 10:eaan5748. doi: 10.1126/scisignal.aan5748

36. Coleman AK, Joca HC, Shi G, Lederer WJ, Ward CW. Tubulin acetylation increases cytoskeletal stiffness to regulate mechanotransduction in striated muscle. J Gen Physiol. (2021) 153:12743. doi: 10.1085/jgp.202012743

37. Gould NR, Williams KM, Joca HC, Torre OM, Lyons JS, Leser JM, et al. Disparate bone anabolic cues activate bone formation by regulating the rapid lysosomal degradation of sclerostin protein. Elife. (2021) 10:e64393. doi: $10.7554 /$ eLife.64393 
38. Goodman C, Hornberger T, Robling A. Bone and skeletal muscle: key players in mechanotransduction and potential overlapping mechanisms. Bone. (2015) 80:24-36. doi: 10.1016/j.bone.2015.04.014

39. Herrmann M, Engelke K, Ebert R, Müller-Deubert S, Rudert M, Ziouti F, et al. Interactions between muscle and bone-where physics meets biology. Biomolecules. (2020) 10:432. doi: 10.3390/biom10030432

40. Gould NR, Torre OM, Leser JM, Stains JP. The cytoskeleton and connected elements in bone cell mechano-transduction. Bone. (2021) 149:115971. doi: 10.1016/j.bone.2021.115971

41. Jin J, Bakker A, Wu G, Klein-Nulend J, Jaspers R. Physicochemical niche conditions and mechanosensing by osteocytes and myocytes. Curr Osteoporos Rep. (2019) 17:235-49. doi: 10.1007/s11914-019-00522-0

42. Wackerhage, H., Schoenfeld, B., Hamilton, D., Lehti, M., and Hulmi, J. (2019). Stimuli and sensors that initiate skeletal muscle hypertrophy following resistance exercise. J Appl Physiol. 126:30-43. doi: 10.1152/japplphysiol.00685.2018

43. Qin L, Liu W, Cao H, Xiao G. Molecular mechanosensors in osteocytes. Bone Res. (2020) 8:23. doi: 10.1038/s41413-020-0099-y

44. Ofek G, Wiltz D, Athanasiou K. Contribution of the cytoskeleton to the compressive properties and recovery behavior of single cells. Biophys J. (2009) 97:1873-82. doi: 10.1016/j.bpj.2009.07.050

45. Roll-Mecak A. How cells exploit tubulin diversity to build functional cellular microtubule mosaics. Curr Opin Cell Biol. (2019) 56:102-8. doi: 10.1016/j.ceb.2018.10.009

46. Janke C, Magiera M. The tubulin code and its role in controlling microtubule properties and functions. Nat Rev. (2020) 21:307-26. doi: 10.1038/s41580-020-0214-3

47. Whitehead N, Yeung E, Froehner S, Allen D. Skeletal muscle NADPH oxidase is increased and triggers stretch-induced damage in the mdx mouse. PLoS ONE. (2010) 5:e0015354. doi: 10.1371/journal.pone.0015354

48. Pal R, Palmieri M, Loehr J, Li S, Abo-Zahrah R, Monroe T, et al. Src-dependent impairment of autophagy by oxidative stress in a mouse model of Duchenne muscular dystrophy. Nat Commun. (2014) 5:5425. doi: 10.1038/ncomms5425

49. Burr A, Molkentin J. Genetic evidence in the mouse solidifies the calcium hypothesis of myofiber death in muscular dystrophy. Cell Death Differ. (2015) 22:1402-12. doi: 10.1038/cdd.2015.65

50. Hyatt H, Powers S. Disturbances in calcium homeostasis promotes skeletal muscle atrophy: lessons from ventilator-induced diaphragm wasting. Front Physiol. (2020) 11:615351. doi: 10.3389/fphys.2020.615351

51. Kular J, Tickner J, Chim SM, Xu J. An overview of the regulation of bone remodelling at the cellular level. Clin Biochem. (2012) 45:863-73. doi: 10.1016/j.clinbiochem.2012.03.021

52. Robling AG, Niziolek PJ, Baldridge LA, Condon KW, Allen MR, Alam $\mathrm{I}$, et al. Mechanical stimulation of bone in vivo reduces osteocyte expression of Sost/sclerostin. J Biol Chem. (2008) 283:5866-75. doi: 10.1074/jbc.M705092200

53. Sato T, Verma S, Andrade CDC, Omeara M, Campbell N, Wang JS, et al. A FAK/HDAC5 signaling axis controls osteocyte mechanotransduction. Nat Commun. (2020) 11:1-18. doi: 10.1038/s41467-020-17099-3

54. Lin C, Jiang X, Dai Z, Guo X, Weng T, Wang J, et al. Sclerostin mediates bone response to mechanical unloading through antagonizing Wnt/beta-catenin signaling. J Bone Mineral Res. (2009) 24:1651-61. doi: 10.1359/jbmr.090411

55. Spatz J, Wein M, Gooi J, Qu Y, Garr J, Liu S, et al. The Wnt inhibitor sclerostin is up-regulated by mechanical unloading in osteocytes in vitro. J Biol Chem. (2015) 290:16744-58. doi: 10.1074/jbc.M114.628313

56. Warden SJ, Roosa SMM, Kersh ME, Hurd AL, Fleisig GS, Pandy MG, et al. Physical activity when young provides lifelong benefits to cortical bone size and strength in men. Proc Nat Acad Sci USA. (2014) 111:5337-42. doi: 10.1073/pnas.1321605111

57. Pickering M, Simon M, Sornay-Rendu E, Chikh K, Carlier M, Raby A, et al. Serum sclerostin increases after acute physical activity. Calcif Tissue Int. (2017) 101:170-3. doi: 10.1007/s00223-017-0272-5

58. Amrein K, Amrein S, Drexler C, Dimai HP, Dobnig H, Pfeifer K, et al. Sclerostin and its association with physical activity, age, gender, body composition, and bone mineral content in healthy adults. J Clin Endocrinol Metab. (2012) 97:148-54. doi: 10.1210/jc.2011-2152
59. Jastrzebski S, Kalinowski J, Stolina M, Mirza F, Torreggiani E, Kalajzic I, et al. Changes in bone sclerostin levels in mice after ovariectomy vary independently of changes in serum sclerostin levels. J Bone Mineral Res. (2013) 28:618-26. doi: 10.1002/jbmr.1773

60. Spatz JM, Fields EE, Yu EW, Pajevic PD, Bouxsein ML, Sibonga JD, et al. Serum sclerostin increases in healthy adult men during bed rest. J Clin Endocrinol Metab. (2012) 97:E1736. doi: 10.1210/jc.2012-1579

61. Baar K, Esser K. Phosphorylation of p70(S6k) correlates with increased skeletal muscle mass following resistance exercise. Am J Physiol. (1999) 276:120. doi: 10.1152/ajpcell.1999.276.1.C120

62. Goodman C. The role of mTORC1 in regulating protein synthesis and skeletal muscle mass in response to various mechanical stimuli. Rev Physiol Biochem Pharmacol. (2014) 166:43-95. doi: 10.1007/112_2013_17

63. Aguilar-Agon K, Capel A, Martin N, Player D, Lewis M. Mechanical loading stimulates hypertrophy in tissue-engineered skeletal muscle: molecular and phenotypic responses. J Cell Physiol. (2019) 234:23547-58. doi: $10.1002 /$ jcp. 28923

64. Phillips S, Tipton K, Aarsland A, Wolf S, Wolfe R. Mixed muscle protein synthesis and breakdown after resistance exercise in humans. Am J Physiol. (1997) 273:e99. doi: 10.1152/ajpendo.1997.273.1.E99

65. Areta J, Burke L, Ross M, Camera D, West DW, Broad EM, et al. Timing and distribution of protein ingestion during prolonged recovery from resistance exercise alters myofibrillar protein synthesis. J Physiol. (2013) 591:2319-31. doi: 10.1113/jphysiol.2012.244897

66. Zanou N, Gailly P. Skeletal muscle hypertrophy and regeneration: interplay between the myogenic regulatory factors (MRFs) and insulinlike growth factors (IGFs) pathways. Cell Mol Life Sci. (2013) 70:4117-30. doi: 10.1007/s00018-013-1330-4

67. Armstrong D, Esser K. Wnt/beta-catenin signaling activates growth-control genes during overload-induced skeletal muscle hypertrophy. Am J Physiol Cell Physiol. (2005) 289:C853-9. doi: 10.1152/ajpcell.00093.2005

68. Carapeto PV, Aguayo-Mazzucato C. Effects of exercise on cellular and tissue aging. Aging. (2021) 13:14522. doi: 10.18632/aging.203051

69. Philp A, Saner N, Lazarou M, Ganley I, Philp A. The influence of aerobic exercise on mitochondrial quality control in skeletal muscle. J Physiol. (2021) 599:3463-76. doi: 10.1113/JP279411

70. Ferreira R, Neuparth M, Vitorino R, Appell H, Amado F, Duarte J. Evidences of apoptosis during the early phases of soleus muscle atrophy in hindlimb suspended mice. Physiol Res. (2008) 57:601-11. doi: $10.33549 /$ physiolres. 931272

71. Peres-Ueno M, Stringhetta-Garcia C, Castoldi R, Ozaki G, ChavesNeto A, Dornelles R, et al. Model of hindlimb unloading in adult female rats: Characterizing bone physicochemical, microstructural, and biomechanical properties. PLoS ONE. (2017) 12:e0189121. doi: 10.1371/journal.pone.0189121

72. Agrawal A, Suryakumar G, Rathor R. Role of defective $\mathrm{Ca}^{2+}$ signaling in skeletal muscle weakness: Pharmacological implications. J Cell Commun Signal. (2018) 12:645-59. doi: 10.1007/s12079-018-0477-z

73. Booth F, Kelso J. Effect of hind-limb immobilization on contractile and histochemical properties of skeletal muscle. Pflugers Archiv. (1973) 342:2318. doi: 10.1007/BF00591371

74. Thayer R, Collins J, Noble E, Taylor A. A decade of aerobic endurance training: histological evidence for fibre type transformation. $J$ Sports Med Phys Fitness. (2000) 40:284-9.

75. Topp R, Ditmyer M, King K, Doherty K, Hornyak J. The effect of bed rest and potential of prehabilitation on patients in the intensive care unit. AACN Clin Issues. (2002) 13:263-76. doi: 10.1097/00044067-200205000-00011

76. Ruegg D, Kakebeeke T, Gabriel J, Bennefeld M. Conduction velocity of nerve and muscle fiber action potentials after a space mission or a bed rest. Clin Neurophysiol. (2003) 114:86-93. doi: 10.1016/S1388-2457(02)00329-2

77. Parry S, Puthucheary Z. The impact of extended bed rest on the musculoskeletal system in the critical care environment. Extr Physiol Med. (2015) 4:16. doi: 10.1186/s13728-015-0036-7

78. Colavitti R, Finkel T. Reactive oxygen species as mediators of cellular senescence. IUBMB Life. (2005) 57:277-81. doi: 10.1080/15216540500091890

79. van Deursen JM. The role of senescent cells in ageing. Nature. (2014) 509:439-46. doi: 10.1038/nature13193 
80. Kim H-N, Chang J, Shao L, Han L, Iyer S, Manolagas SC, et al. DNA damage and senescence in osteoprogenitors expressing Osx1 may cause their decrease with age. Aging Cell. (2017) 16:693-703. doi: 10.1111/acel.12597

81. Farr JN, Xu M, Weivoda MM, Monroe DG, Fraser DG, Onken JL, et al. Targeting cellular senescence prevents age-related bone loss in mice. Nat Med. (2017) 23:1072-9. doi: 10.1038/nm.4385

82. Sousa-Victor P, Gutarra S, García-Prat L, Rodriguez-Ubreva J, Ortet L, RuizBonilla V, et al. Geriatric muscle stem cells switch reversible quiescence into senescence. Nature. (2014) 506:316-21. doi: 10.1038/nature13013

83. Baar MP, Perdiguero E, Muñoz-Cánoves P, de Keizer PL. Musculoskeletal senescence: a moving target ready to be eliminated. Curr Opin Pharmacol. (2018) 40:147-55. doi: 10.1016/j.coph.2018.05.007

84. Kregel $\mathrm{K}$, Zhang $\mathrm{H}$. An integrated view of oxidative stress in aging: basic mechanisms, functional effects, and pathological considerations. Am J Physiol Regul Integr Compar Physiol. (2007) 292:R18-36. doi: 10.1152/ajpregu.00327.2006

85. Victorelli S, Passos J. Reactive oxygen species detection in senescent cells. Methods Mol Biol. (2019) 1896:21-9. doi: 10.1007/978-1-4939-8931-7_3

86. Morgan MJ, Liu Z. Crosstalk of reactive oxygen species and NF- $\kappa B$ signaling. Cell Res. (2010) 21:103-15. doi: 10.1038/cr.2010.178

87. Almeida M, Han L, Martin-Millan M, Plotkin LI, Stewart SA, Roberson $\mathrm{PK}$, et al. Skeletal involution by age-associated oxidative stress and its acceleration by loss of sex steroids. J Biol Chem. (2007) 282:27285-97. doi: 10.1074/jbc.M702810200

88. Sharma T, Islam N, Ahmad J, Akhtar N, Beg M. Correlation between bone mineral density and oxidative stress in postmenopausal women. Indian J Endocrinol Metab. (2015) 19:491-7. doi: 10.4103/2230-8210.159053

89. Bonaccorsi G, Piva I, Greco P, Cervellati C. Oxidative stress as a possible pathogenic cofactor of post-menopausal osteox porosis: Existing evidence in support of the axis oestrogen deficiency-redox imbalance-bone loss. Indian J Med Res. (2018) 147:341-51. doi: 10.4103/ijmr.IJMR_524_18

90. Petr MA, Alfaras I, Krawcyzk M, Bair WN, Mitchell SJ, Morrell CH, et al. A cross-sectional study of functional and metabolic changes during aging through the lifespan in male mice. Elife. (2021) 10:e62952. doi: 10.7554/eLife.62952

91. Baylis D, Bartlett D, Patel H, Roberts H. Understanding how we age: insights into inflammaging. Longevity Healthspan. (2013) 2:8. doi: 10.1186/2046-2395-2-8

92. Michaud M, Balardy L, Moulis G, Gaudin C, Peyrot C, Vellas B, et al. Proinflammatory cytokines, aging, and age-related diseases. J Am Med Dir Assoc. (2013) 14:877-82. doi: 10.1016/j.jamda.2013.05.009

93. Singh N, Baby D, Rajguru J, Patil P, Thakkannavar S, Pujari V. Inflammation and cancer. Ann Afr Med. (2019) 18:121-6. doi: 10.4103/aam.aam_56_18

94. Marahleh A, Kitaura H, Ohori F, Kishikawa A, Ogawa S, Shen W, et al. TNF$\alpha$ directly enhances osteocyte RANKL expression and promotes osteoclast formation. Front Immunol. (2019) 10:2925. doi: 10.3389/fimmu.2019.02925

95. Baker-LePain J, Nakamura M, Lane N. Effects of inflammation on bone: an update. Curr Opin Rheumatol. (2011) 23:389-95. doi: 10.1097/BOR.0b013e3283474dbe

96. Iannuzzi-Sucich M, Prestwood KM, Kenny AM. Prevalence of sarcopenia and predictors of skeletal muscle mass in healthy, older men and women. $J$ Gerontol. (2002) 57:772-7. doi: 10.1093/gerona/57.12.M772

97. Ferrucci L, Fabbri E. Inflammageing: chronic inflammation in ageing, cardiovascular disease, and frailty. Nat Rev Cardiol. (2018) 15:505-22. doi: 10.1038/s41569-018-0064-2

98. Tsujinaka T, Fujita J, Ebisui C, Yano M, Kominami E, Suzuki K, et al. Interleukin 6 receptor antibody inhibits muscle atrophy and modulates proteolytic systems in interleukin 6 transgenic mice. J Clin Invest. (1996) 97:244-9. doi: 10.1172/JCI118398

99. Josephson AM, Bradaschia-Correa V, Lee S, Leclerc K, Patel KS, Lopez EM, et al. Age-related inflammation triggers skeletal stem/progenitor cell dysfunction. Proc Nat Acad Sci USA. (2019) 116:6995-7004. doi: $10.1073 /$ pnas. 1810692116

100. Bharath LP, Agrawal M, McCambridge G, Nicholas DA, Hasturk H, Liu J, et al. Metformin enhances autophagy and normalizes mitochondrial function to alleviate aging-associated inflammation. Cell Metabol. (2020) 32:44-55.e6. doi: 10.1016/j.cmet.2020.04.015
101. Lin J, Xu R, Shen X, Jiang H, Du S. Metformin promotes the osseointegration of titanium implants under osteoporotic conditions by regulating BMSCs autophagy, and osteogenic differentiation. Biochem Biophys Res Commun. (2020) 531:228-35. doi: 10.1016/j.bbrc.2020.06.146

102. Jeyabalan J, Viollet B, Smitham P, Ellis S, Zaman G, Bardin C, et al. The anti-diabetic drug metformin does not affect bone mass in vivo or fracture healing. Osteoporosis Int. (2013) 24:2659-70. doi: 10.1007/s00198-013-2371-0

103. Gao Y, Li Y, Xue J, Jia Y, Hu J. Effect of the anti-diabetic drug metformin on bone mass in ovariectomized rats. Eur J Pharmacol. (2010) 635:231-6. doi: 10.1016/j.ejphar.2010.02.051

104. Molinuevo M, Schurman L, McCarthy A, Cortizo A, Tolosa M, Gangoiti M, et al. Effect of metformin on bone marrow progenitor cell differentiation: in vivo and in vitro studies. J Bone Min Res. (2010) 25:211-21. doi: 10.1359/jbmr.090732

105. Bahrambeigi S, Yousefi B, Rahimi M, Shafiei-Irannejad V. Metformin; an old antidiabetic drug with new potentials in bone disorders. Biomed Pharmacother. (2019) 109:1593-601. doi: 10.1016/j.biopha.2018.11.032

106. Shah M, Kola B, Bataveljic A, Arnett TR, Viollet B, Saxon L, et al. AMPactivated protein kinase (AMPK) activation regulates in vitro bone formation and bone mass. Bone. (2010) 47:309. doi: 10.1016/j.bone.2010.04.596

107. Kulkarni A, Peck B, Walton R, Kern P, Mar J, Windham S, et al. Metformin alters skeletal muscle transcriptome adaptations to resistance training in older adults. Aging. (2020) 12:19852-66. doi: 10.18632/aging.104096

108. Pesce M, Ballerini P, Paolucci T, Puca I, Farzaei M, Patruno A. Irisin and autophagy: first update. Int J Mol Sci. (2020) 21:1-27. doi: 10.3390/ijms21207587

109. Nixon RA. The aging lysosome: An essential catalyst for late-onset neurodegenerative diseases. Biochim Biophys Acta Proteins Proteom. (2020) 1868:140443. doi: 10.1016/j.bbapap.2020.140443

110. Ciechanover A, Kwon Y. Degradation of misfolded proteins in neurodegenerative diseases: therapeutic targets and strategies. Exp Mol Med. (2015) 47:e147. doi: 10.1038/emm.2014.117

111. Wang W, Roberts C. Protein aggregation - mechanisms, detection, and control. Int J Pharm. (2018) 550:251-68. doi: 10.1016/j.ijpharm.2018.08.043

112. Onal M, Piemontese M, Xiong J, Wang Y, Han L, Ye S, et al. Suppression of autophagy in osteocytes mimics skeletal aging. J Biol Chem. (2013) 288:17432-40. doi: 10.1074/jbc.M112.444190

113. Ma Y, Qi M, An Y, Zhang L, Yang R, Doro D, et al. Autophagy controls mesenchymal stem cell properties and senescence during bone aging. Aging cell. (2018) 17:12709. doi: 10.1111/acel.12709

114. Liu Z, Hong C, Hu W, Chen M, Duan R, Li H, et al. Autophagy receptor OPTN (optineurin) regulates mesenchymal stem cell fate and bone-fat balance during aging by clearing FABP3. Autophagy. (2020) 17:2766-82. doi: 10.1080/15548627.2020.1839286

115. Zhou J, Chong SY, Lim A, Singh BK, Sinha RA, Salmon AB, et al. Changes in macroautophagy, chaperone-mediated autophagy, and mitochondrial metabolism in murine skeletal and cardiac muscle during aging. Aging. (2017) 9:583-99. doi: 10.18632/aging.101181

116. Ren J, Zhang Y. Targeting autophagy in aging and aging-related cardiovascular diseases. Trends Pharmacol Sci. (2018) 39:1064-76. doi: 10.1016/j.tips.2018.10.005

117. Panicker L, Srikanth M, Castro-Gomes T, Miller D, Andrews N, Feldman R. Gaucher disease iPSC-derived osteoblasts have developmental and lysosomal defects that impair bone matrix deposition. Gaucher disease iPSC-derived osteoblasts have developmental and lysosomal defects. Human Mol Gene. (2018) 27:811-22. doi: 10.1093/hmg/ddx442

118. Inoki K, Li Y, Zhu T, Wu J, Guan K. TSC2 is phosphorylated and inhibited by Akt and suppresses mTOR signalling. Nat Cell Biol. (2002) 4:648-57. doi: $10.1038 /$ ncb839

119. García-Prat L, Muñoz-Cánoves P, Martinez-Vicente M. Dysfunctional autophagy is a driver of muscle stem cell functional decline with aging. Autophagy. (2016) 12:612-3. doi: 10.1080/15548627.2016.1143211

120. Huang D, Yan X, Fan SD, Chen XY, Yan JY, Dong QT, et al. Nrf2 deficiency promotes the increasing trend of autophagy during aging in skeletal muscle: a potential mechanism for the development of sarcopenia. Aging. (2020) 12:5977-91. doi: 10.18632/aging.102990 
121. Triolo M, Hood D. Manifestations of age on autophagy, mitophagy and lysosomes in skeletal muscle. Cells. (2021) 10. doi: 10.3390/cells10051054

122. Boppart M, Burkin D, Kaufman S. Alpha7betal-integrin regulates mechanotransduction and prevents skeletal muscle injury. Am J Physiol Cell Physiol. (2006) 290:317. doi: 10.1152/ajpcell.00317.2005

123. Formigli L, Sassoli C, Squecco R, Bini F, Martinesi M, Chellini F, et al. Regulation of transient receptor potential canonical channel 1 (TRPC1) by sphingosine 1-phosphate in $\mathrm{C} 2 \mathrm{C} 12$ myoblasts and its relevance for a role of mechanotransduction in skeletal muscle differentiation. J Cell Sci. (2009) 122:1322-33. doi: $10.1242 /$ jcs. 035402

124. Zhang J, Zhao Y, Liu C, Han E, Yu X, Lidington D, et al. The role of the sphingosine-1-phosphate signaling pathway in osteocyte mechanotransduction. Bone. (2015) 79:71-8. doi: 10.1016/j.bone.2015.05.017

125. Fischer M, Rikeit P, Knaus P, Coirault C. YAP-mediated mechanotransduction in skeletal muscle. Front Physiol. (2016) 7:41. doi: $10.3389 /$ fphys.2016.00041

126. Wu X, Sun L, Yang X, Ding D, Han D, Fan Y. The potential role of spectrin network in the mechanotransduction of MLO-Y4 osteocytes. Sci Rep. (2017) 7:40940. doi: 10.1038/srep40940

127. Yu K, Sellman D, Bahraini A, Hagan M, Elsherbini A, Vanpelt K, et al. Mechanical loading disrupts osteocyte plasma membranes which initiates mechanosensation events in bone. J Orthopaedic Res. (2018) 36:653-62. doi: 10.1002/jor.23665

128. Lewis K, Yi X, Wright C, Pemberton E, Bullock W, Thompson W, et al. The mTORC2 component rictor is required for load-induced bone formation in late-stage skeletal cells. JBMR Plus. (2020) 4:10366. doi: 10.1002/jbm4.10366

129. Mu X, Tseng C, Hambright W, Matre P, Lin C, Chanda P, et al. Cytoskeleton stiffness regulates cellular senescence and innate immune response in Hutchinson-Gilford Progeria Syndrome. Aging Cell. (2020) 19:13152. doi: 10.1111 /acel.13152

130. Gilbert HTJ, Swift J. The consequences of ageing, progeroid syndromes and cellular senescence on mechanotransduction and the nucleus. Exp Cell Res. (2019) 378:98-103. doi: 10.1016/j.yexcr.2019.03.002

131. Moujaber O, Fishbein F, Omran N, Liang Y, Colmegna I, Presley $\mathrm{JF}$, et al. Cellular senescence is associated with reorganization of the microtubule cytoskeleton. Cell Mol Life Sci. (2019) 76:1169-83. doi: 10.1007/s00018-018-2999-1

132. Doolittle M, Monroe D, Farr J, Khosla S. The role of senolytics in osteoporosis and other skeletal pathologies. Mech Ageing Dev. (2021) 199:111565. doi: 10.1016/j.mad.2021.111565

133. Wan M, Gray-Gaillard E, Elisseeff J. Cellular senescence in musculoskeletal homeostasis, diseases, and regeneration. Bone Res. (2021) 9:41. doi: 10.1038/s41413-021-00164-y

134. Wilson C, González-Billault C. Regulation of cytoskeletal dynamics by redox signaling and oxidative stress: implications for neuronal development and trafficking. Front Cell Neurosci. (2015) 9:381. doi: 10.3389/fncel.2015.00381

135. Goldblum R, McClellan M, White K, Gonzalez S, Thompson B, Vang H, et al. Oxidative stress pathogenically remodels the cardiac myocyte cytoskeleton via structural alterations to the microtubule lattice. Dev Cell. (2021) 56:225266.e6. doi: 10.1016/j.devcel.2021.07.004

136. Zhu W, Kim B, Wang $M$, Huang J, Isak A, Bexiga N, et al. TGF $\beta 1$ reinforces arterial aging in the vascular smooth muscle cell through a long-range regulation of the cytoskeletal stiffness. Sci Rep. (2018) 8:2668. doi: 10.1038/s41598-018-20763-w

137. Petrache I, Birukova A, Ramirez S, Garcia J, Verin A. The role of the microtubules in tumor necrosis factor-alpha-induced endothelial cell permeability. Am J Respir Cell Mol Biol. (2003) 28:574-81. doi: 10.1165/rcmb.2002-0075OC

138. Bakker AD, da Silva VC, Krishnan R, Bacabac RG, Blaauboer ME, Lin Y-C, et al. Tumor necrosis factor $\alpha$ and interleukin- $1 \beta$ modulate calcium and nitric oxide signaling in mechanically stimulated osteocytes. Arthritis Rheum. (2009) 60:3336-45. doi: 10.1002/art.24920

139. Matzelle MM, Gallant MA, Condon KW, Walsh NC, Manning CA, Stein GS, et al. Resolution of inflammation induces osteoblast function and regulates the Wnt signaling pathway. Arthritis Rheum. (2012) 64:1540-50. doi: 10.1002/art.33504
140. Roubille F, Kritikou E, Busseuil D, Barrere-Lemaire S, Tardif J. Colchicine: an old wine in a new bottle? Antiinflamm Antiallergy Agents Med Chem. (2013) 12:14-23. doi: 10.2174/1871523011312010004

141. Nidorf SM, Fiolet ATL, Eikelboom JW, Schut A, Opstal TSJ, Bax WA, et al. The effect of low-dose colchicine in patients with stable coronary artery disease: the LoDoCo2 trial rationale, design, and baseline characteristics. Am Heart J. (2019) 218:46-56. doi: 10.1016/j.ahj.2019. 09.011

142. Caporizzo MA, Chen CY, Bedi K, Margulies KB, Prosser BL. Microtubules increase diastolic stiffness in failing human cardiomyocytes and myocardium. Circulation. (2020) 141:902. doi: 10.1161/CIRCULATIONAHA.119.043930

143. Carletti B, Passarelli C, Sparaco M, Tozzi G, Pastore A, Bertini E, et al. Effect of protein glutathionylation on neuronal cytoskeleton: a potential link to neurodegeneration. Neuroscience. (2011) 192:285-94. doi: 10.1016/j.neuroscience.2011.05.060

144. Yu B, Pacureanu A, Olivier C, Cloetens P, Peyrin F. Assessment of the human bone lacuno-canalicular network at the nanoscale and impact of spatial resolution. Sci Rep. (2020) 10:4567. doi: 10.1038/s41598-020-61269-8

145. Anderson E, Kaliyamoorthy S, Iwan J, Alexander D, Knothe Tate M. Nano-microscale models of periosteocytic flow show differences in stresses imparted to cell body and processes. Ann Biomed Eng. (2005) 33:52-62. doi: 10.1007/s10439-005-8962-y

146. Palumbo C, Ferretti M. The osteocyte: from "prisoner" to "orchestrator." $J$ Funct Morphol Kinesiol. (2021) 6:28. doi: 10.3390/jfmk6010028

147. Tiede-Lewis LAM, Xie Y, Hulbert MA, Campos R, Dallas MR, Dusevich $\mathrm{V}$, et al. Degeneration of the osteocyte network in the C57BL/6 mouse model of aging. Aging. (2017) 9:2187-205. doi: 10.18632/aging. 101308

148. Xiao J, Zhao H, Liang D, Liu Y, Zhang H, Liu Y, et al. Taxol, a microtubule stabilizer, improves cardiac contractile function during ischemia in vitro. Pharmacology. (2010) 85:301-10. doi: 10.1159/000292948

149. Cao H, Wang Y, Wang Q, Wang R, Guo S, Zhao X, et al. Taxol prevents myocardial ischemia-reperfusion injury by inducing JNK-mediated HO-1 expression. Pharm Biol. (2016) 54:555-60.

150. Pu J, Guardia C, Keren-Kaplan T, Bonifacino J. Mechanisms and functions of lysosome positioning. J Cell Sci. (2016) 129:4329-39. doi: 10.1242/jcs.196287

151. Hollenbeck P, Swanson J. Radial extension of macrophage tubular lysosomes supported by kinesin. Nature. (1990) 346:864-6. doi: 10.1038/346864a0

152. Harada A, Takei Y, Kanai Y, Tanaka Y, Nonaka S, Hirokawa N. Golgi vesiculation and lysosome dispersion in cells lacking cytoplasmic dynein. $J$ Cell Biol. (1998) 141:51-9. doi: 10.1083/jcb.141.1.51

153. Reed N, Cai D, Blasius T, Jih G, Meyhofer E, Gaertig J, et al. Microtubule acetylation promotes kinesin-1 binding and transport. Current Biol. (2006) 16:2166-72. doi: 10.1016/j.cub.2006.09.014

154. Ikegami K, Heier R, Taruishi M, Takagi H, Mukai M, Shimma S, et al. Loss of alpha-tubulin polyglutamylation in ROSA22 mice is associated with abnormal targeting of KIF1A and modulated synaptic function. Proc Natl Acad Sci USA. (2007) 104:3213-8. doi: 10.1073/pnas.0611547104

155. Dunn S, Morrison S, Liverpool E, Molina-París T, Cross C, Alonso R, et al. Differential trafficking of Kif5c on tyrosinated and detyrosinated microtubules in live cells. J Cell Sci. (2008) 121:1085-95. doi: $10.1242 /$ jcs. 026492

156. Hagiwara H, Yorifuji H, Sato-Yoshitake R, Hirokawa N. Competition between motor molecules (kinesin and cytoplasmic dynein) and fibrous microtubule-associated proteins in binding to microtubules. J Biol Chem. (1994) 269:3581-9. doi: 10.1016/S0021-9258(17)41903-X

157. Trinczek B, Ebneth A, Mandelkow E, Mandelkow E. Tau regulates the attachment/detachment but not the speed of motors in microtubuledependent transport of single vesicles and organelles. J Cell Sci. (1999) 112:2355-67. doi: 10.1242/jcs.112.14.2355

158. Mohan N, Sorokina EM, Verdeny IV, Alvarez AS, Lakadamyali M. Detyrosinated microtubules spatially constrain lysosomes facilitating lysosome-autophagosome fusion. J Cell Biol. (2019) 218:632-43. doi: $10.1083 /$ jcb.201807124

159. Caserotti P, Aagaard P, Puggaard L. Changes in power and force generation during coupled eccentric-concentric versus concentric muscle 
contraction with training and aging. Eur J Appl Physiol. (2008) 103:151-61. doi: 10.1007/s00421-008-0678-x

160. Gremeaux V, Gayda M, Lepers R, Sosner P, Juneau M, Nigam A. Exercise and longevity. Maturitas. (2012) 73:312-7. doi: 10.1016/j.maturitas.2012.09.012

161. Garatachea N, Pareja-Galeano H, Sanchis-Gomar F, Santos-Lozano A, FiuzaLuces C, Morán M, et al. Exercise attenuates the major hallmarks of aging. Rejuvenation Res. (2015) 18:57-89. doi: 10.1089/rej.2014.1623

162. Gardinier JD, Rostami N, Juliano L, Zhang C. Bone adaptation in response to treadmill exercise in young and adult mice. Bone Rep. (2018) 8:29-37. doi: 10.1016/j.bonr.2018.01.003

163. Pedersen B. Which type of exercise keeps you young? Curr Opin Clin Nutr Metab Care. (2019) 22:167-73. doi: 10.1097/MCO.0000000000000546

164. Chen X, Yi Z, Wong G, Hasan K, Kwan J, Ma A, et al. Is exercise a senolytic medicine? A systematic review. Aging cell. (2021) 20:13294. doi: 10.1111/acel.13294

165. Sherk VD, Rosen CJ. Senescent and apoptotic osteocytes and aging: exercise to the rescue? Bone. (2019) 121:255-8. doi: 10.1016/j.bone.2019.02.006

166. Bouviere J, Fortunato RS, Dupuy C, Werneck-de-Castro JP, Carvalho DP, Louzada RA. Exercise-stimulated ROS sensitive signaling pathways in skeletal muscle. Antioxidants. (2021) 10:537. doi: 10.3390/antiox10040537

167. Walton R, Dungan C, Long D, Tuggle S, Kosmac K, Peck B, et al. Metformin blunts muscle hypertrophy in response to progressive resistance exercise training in older adults: a randomized, double-blind, placebocontrolled, multicenter trial: the MASTERS trial. Aging Cell. (2019) 18:13039. doi: 10.1111/acel.13039

168. Kang C, Chung E, Diffee G, Ji LL. Exercise training attenuates agingassociated mitochondrial dysfunction in rat skeletal muscle: role of PGC-1 $\alpha$. Exp Gerontol. (2013) 48:1343-50. doi: 10.1016/j.exger.2013.08.004

169. Halling J, Ringholm S, Nielsen M, Overby P, Pilegaard H. PGC-1 $\alpha$ promotes exercise-induced autophagy in mouse skeletal muscle. Physiol Rep. (2016) 4:12698. doi: 10.14814/phy2.12698

170. Blackwell J, Gharahdaghi N, Brook M, Watanabe S, Boereboom C, Doleman $\mathrm{B}$, et al. The physiological impact of high-intensity interval training in octogenarians with comorbidities. J Cachexia Sarcopenia Muscle. (2021) 12:866-79. doi: 10.1002/jcsm.12724

171. Dethlefsen MM, Halling JF, Møller HD, Plomgaard P, Regenberg B, Ringholm S, et al. Regulation of apoptosis and autophagy in mouse and human skeletal muscle with aging and lifelong exercise training. Exp Gerontol. (2018) 111:141-53. doi: 10.1016/j.exger.2018.07.011

172. He C, Sumpter R, Levine B. Exercise induces autophagy in peripheral tissues and in the brain. Autophagy. (2012) 8:1548-51. doi: 10.4161/auto.21327

173. Rocchi A, He C. Regulation of exercise-induced autophagy in skeletal muscle. Curr Pathobiol Rep. (2017) 5:177-86. doi: 10.1007/s40139-017-0135-9

174. Liang J, Zeng Z, Zhang Y, Chen N. Regulatory role of exerciseinduced autophagy for sarcopenia. Exp Gerontol. (2020) 130:110789. doi: 10.1016/j.exger.2019.110789

175. Fassett JT, Hu X, Xu X, Lu Z, Zhang P, Chen Y, et al. AMPK attenuates microtubule proliferation in cardiac hypertrophy. Am J Physiol. (2013) 304:H749. doi: 10.1152/ajpheart.00935.2011

176. Adams K, O'Shea P, O'Shea KL. Aging: its effects on strength, power, flexibility, and bone density. Anim Res. (2000) 49:65-77. doi: 10.1519/00126548-199904000-00021

177. Häkkinen K, Kraemer WJ, Pakarinen A, Tripleltt-Mcbride T, Mcbride $\mathrm{JM}$, Häkkinen A, et al. Effects of heavy resistance/power training on maximal strength, muscle morphology, and hormonal response patterns in 60-75-year-old men and women. Can J Appl Physiol. (2011) 27:213-31. doi: $10.1139 / \mathrm{h} 02-013$
178. Watson SL, Weeks BK, Weis LJ, Harding AT, Horan SA, Beck BR. Highintensity resistance and impact training improves bone mineral density and physical function in postmenopausal women with osteopenia and osteoporosis: the LIFTMOR randomized controlled trial. J Bone Mineral Res. (2018) 33:211-20. doi: 10.1002/jbmr.3284

179. Fragala MS, Cadore EL, Dorgo S, Izquierdo M, Kraemer WJ, Peterson MD, et al. Resistance training for older adults: Position statement from the national strength and conditioning association. J Strength Cond Res. (2019) 33:2019-52. doi: 10.1519/JSC.0000000000003230

180. Harding AT, Weeks BK, Lambert C, Watson SL, Weis LJ, Beck BR. A comparison of bone-targeted exercise strategies to reduce fracture risk in middle-aged and older men with osteopenia and osteoporosis: LIFTMORM semi-randomized controlled trial. J Bone Mineral Res. (2020) 35:1404-14. doi: $10.1002 / \mathrm{jbmr} .4008$

181. Li Y, Wang X, Zhang R, Zhu S, Wang L, Huang J, et al. Comparative effectiveness of different exercises on bone mineral density in postmenopausal women: a systematic review and network metaanalysis of randomized controlled trials. medRxiv [Preprint]. (2021). doi: 10.1101/2021.07.12.21260370

182. He C, He W, Hou J, Chen K, Huang M, Yang M, et al. Bone and muscle crosstalk in aging. Front Cell Dev Biol. (2020) 8:585644. doi: $10.3389 /$ fcell.2020.585644

183. Kwon J, Moon K, Min K. Exercise-induced myokines can explain the importance of physical activity in the elderly: an overview. Healthcare. (2020) 8:378. doi: $10.3390 /$ healthcare 8040378

184. Chen W, Wang L, You W, Shan T. Myokines mediate the cross talk between skeletal muscle and other organs. J Cell Physiol. (2021) 236:2393-412. doi: $10.1002 /$ jcp. 30033

185. Leuchtmann A, Adak V, Dilbaz S, Handschin C. The role of the skeletal muscle secretome in mediating endurance and resistance training adaptations. Front Physiol. (2021) 12:709807. doi: 10.3389/fphys.2021.709807

Conflict of Interest: JS and CW holds two patents related to this work. One for the custom fluid shear device used for these experiments US Patent No US 2017/0276666 A1 and a second for the targeting microtubules part of this mechano-transduction pathway to improve bone mass US Patent No US 2019/0351055 A1. CW also has another patent pending on colchicine analogs to treat musculoskeletal disorders PCT/US2018/038300.

The remaining authors declare that the research was conducted in the absence of any commercial or financial relationships that could be construed as a potential conflict of interest.

Publisher's Note: All claims expressed in this article are solely those of the authors and do not necessarily represent those of their affiliated organizations, or those of the publisher, the editors and the reviewers. Any product that may be evaluated in this article, or claim that may be made by its manufacturer, is not guaranteed or endorsed by the publisher.

Copyright (c) 2021 Leser, Harriot, Buck, Ward and Stains. This is an open-access article distributed under the terms of the Creative Commons Attribution License (CC $B Y)$. The use, distribution or reproduction in other forums is permitted, provided the original author(s) and the copyright owner(s) are credited and that the original publication in this journal is cited, in accordance with accepted academic practice. No use, distribution or reproduction is permitted which does not comply with these terms. 